\title{
BMJ tablet app
}

\author{
Now available free to subscribers and BMA members without an iTunes account
}

\section{David Payne editor bmj.com, Fiona Godlee editor in chief}

BMJ, London WC1H 9JR, UK

The future of medical information is mobile, and the $B M J$ is investing in its mobile presence. Following the launch or our iTunes app 18 months ago, the journal is now available free to tablet users as part of a personal or institutional subscription. The new "tablet app" is available on the iPad without the need for an iTunes account, and we expect to extend this to other tablet devices in the near future.

The tablet app is being launched as a beta version. It allows personal and institutional subscribers to browse and read the $B M J$ journal, just as they would the weekly print journal but with added interactivity. It includes the same selection of research, education, and comment chosen for each week's print issue, along with a prominent link to bmj.com for the latest news and online articles that have not yet appeared in print. Each article contains clickable graphics, embedded video and audio (where available), as well as links to key related articles from the $B M J$ archive. You can also submit responses by clicking on the "Submit response" button on all articles. Research articles follow the same abridged "pico" format as they do in print, but with links to the full text on bmj.com.

As with our iTunes app, you can download issues to read offline. Find out more at bmj.com/tablet.

The BMJ has a proud history of "firsts" when it comes to digital access. It was the first major general medical journal to have a full text website in 1998, the first to create an iPad app in 2010, the first to move to the Apple Newsstand in 2011, and the first to offer a product of this kind.

We initially decided to launch the tablet app on the iPad because currently that is where most of our mobile traffic comes from. In May 2012, for example, there were 101218 visits to bmj.com from mobile phones and tablet computers. Of that figure, 39 918 were from the iPad. In comparison, 17631 came from all mobile devices using the Android operating system. Interestingly, since December more people have accessed bmj.com from the iPad than from an iPhone (31 915 in May 2012) (figure).

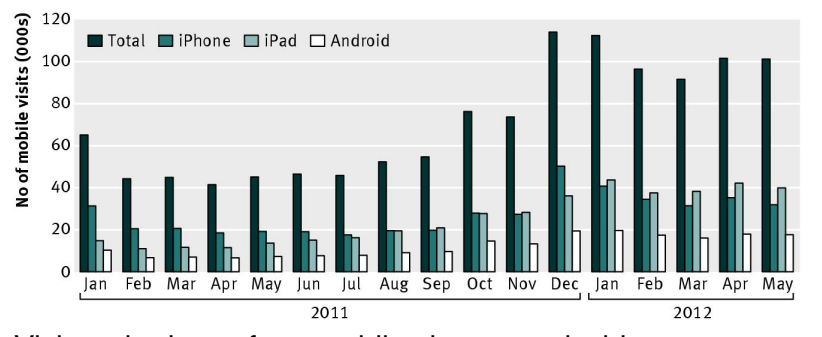

Visits to bmj.com from mobile phones and tablet computers

A high proportion of our visits from mobile devices were from readers outside the United Kingdom. Most, therefore, will probably not have seen a recent print issue. We hope the tablet app is another way of delivering on a pledge to give all our readers the benefit of a weekly bundle of content as well as a sense of our print issue, including the front cover. Many non-UK readers asked for this in our 2010 online survey.

Some consumer publications (such as the Financial Times) have discontinued their iTunes app after launching a web based app of the kind described here, but we have decided to keep our iTunes app. This is because we think it is good to have a presence on the Apple Newsstand, a high profile online store for people with an iTunes account who want to buy a single issue or monthly subscription. We have also made the iTunes app freely available to BMA members (who can also access the tablet app for free). Between January and April 2012, there were 39816 downloads from BMA members.

We hope the new tablet app will be as successful as the iPad app has been, particularly among institutional and personal subscribers.

If your institution does not have a current $B M J$ subscription but you would like one so that you can access the tablet app and bmj.com for free, please email ipad@bmj.com for more details.

Competing interests: Both authors have completed the ICMJE uniform disclosure form at www.icmje.org/coi_disclosure.pdf (available on request from the corresponding author) and declare: no support from any organisation for the submitted work; no financial relationships with any organisations that might have an interest in the submitted work in 
the previous three years; no other relationships or activities that could appear to have influenced the submitted work.

Provenance and peer review: Not commissioned; not externally peer reviewed.
Cite this as: BMJ 2012;345:e4877

๑ BMJ Publishing Group Ltd 2012 